Proc. Indian Acad. Sci. (Chem. Sci.), Vol. 108, No. 3, June 1996, pp. 131-142.

(C) Printed in India.

\title{
Tuning metal-metal distances through ligands
}

\author{
SANTOSH P ABRAHAM and ASHOKA G SAMUELSON* \\ Department of Inorganic and Physical Chemistry, Indian Institute of Science, \\ Bangalore 560012, India
}

\begin{abstract}
Metal-metal distances in polynuclear metal complexes are often controlled by factors other than favourable metal-metal (M-M) interactions. Recently metal cluster topology has been identified as a major factor in controlling $\mathrm{Cu} \sim \mathrm{Cu}$ distances in tetrahedral copper clusters. The more obvious ligand control in $\mathrm{M}-\mathrm{M}$ distances was shown to play a secondary role. In order to probe ways to tune metal-metal distances in clusters, a study of clusters with similar ligands around the metal has been taken up. Two broad classes were identified: Clusters in which there are two-electron two-centre bonds, and a second class where multicentre multielectron bridging is involved.

Clusters held together by two-electron two-centre bonds can be analysed fairly effectively using a test electrophile like the proton. This is illustrated by analysing structures available in the literature. The sensitivity of the method to detect M-M interactions will be illustrated with examples from gold clusters where relativistic interactions cause gold $d^{10}-d^{10}$ interactions to be attractive. Among the latter class $\mathrm{Cu}_{3} \mathrm{P}_{6} \mathrm{X}_{2}$ core makes a specially interesting case study. The capping ligand $\mathrm{X}$ determines the extent of $\mathrm{Cu}-\mathrm{Cu}$ interaction present in the cluster. Simple EHT calculations on the cluster reveal that $\mathrm{Cu}-\mathrm{Cu}$ reduced overlap populations change significantly with the extent of $\pi$-donation or acceptance of the ligand.
\end{abstract}

Keywords. Metal-metal distances; clusters; ligand control; EHT calculations.

\section{Introduction}

Metal-metal bonds are considered an essential feature of metal clusters (Cotton and Wilkinson 1988). Indeed, in several metal clusters one of the major forces is the metal-metal bond. Hence in some instances the chemistry of a metal cluster is said to be determined by the strength of metal-metal bonds. However in many polynuclear metal complexes, where comparable short metal-metal distances exist, metal-metal bonds are nonexistent or questionable at best (Cotton et al 1988). Although short metalmetal contacts exist in these compounds, suggesting at first sight that there are attractive forces between the metal centres, analysis of the $\mathbf{M}-\mathbf{M}$ bond order reveals that there is no net bonding between the two atoms. A few examples of such compounds are listed in figure 1. One must then answer the question, why do these compounds adopt short metal-metal distances? The answer to this question might be sought in the type of bridging ligands present in these complexes. Indeed in polynuclear copper(I) complexes where repulsive $d^{10}-d^{10}$ interactions rule out $\mathrm{M}-\mathrm{M}$ bonding, bridging ligands appear to play a major role in determining M-M distances (Abraham et al 1993). In this study we show that the methodology developed by them can be used, not only to rule out the presence of an M-M bond but also to confirm the presence of

\footnotetext{
*For correspondence
} 


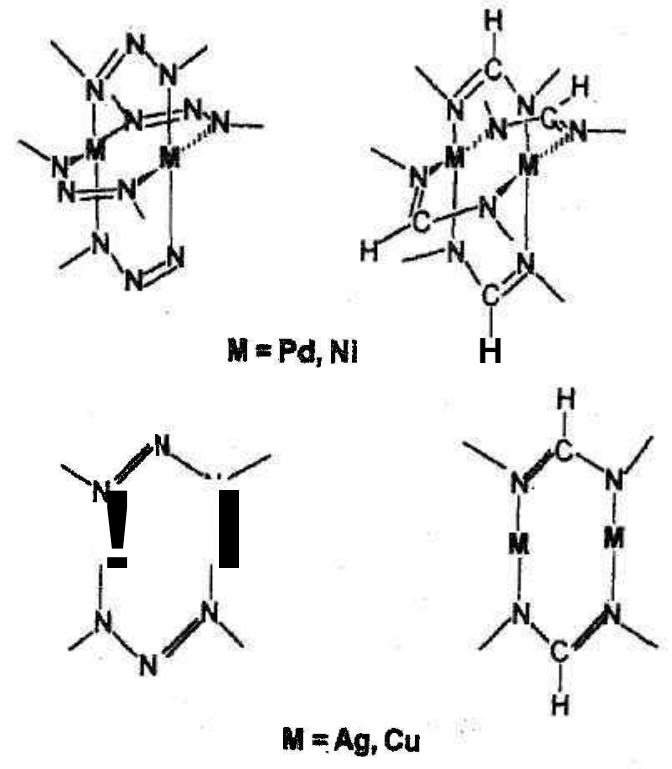

Figure 1. Metal complexes with an M-M bond order of zero.

attractive M-M interactions. Furthermore the possibility of tuning of M-M attractions through electron deficient multicentre bonding can be predicted through simple Extended Huckel Theoretical (EHT) calculations (Hoffman 1963).

\section{Results and discussion}

Most polynuclear metal complexes containing $d^{10}$ metal atoms are held together by the presence of bridging ligands except for a few examples of polynuclear gold complexes which have short M-M contacts in the absence of bridging ligands (Park and Kanatzidis 1990). Such unsupported short contacts are not known with other $d^{10}$ metal ions. A careful analysis of the various polynuclear $d^{10}$ clusters shows that there are two types of bridges holding the metal centres together. The first type involves metal centres bridged by the ligand through two-centre two-electron bonds. The second type involves monoatomic bridges formed by atoms such as $\mathrm{S}$ and $\mathrm{Cl}$. The role of these bridges in determining M-M distances in oligomeric complexes has to be discussed separately.

\subsection{Electron precise metal-ligandbridging}

In complexes where the metal centres are bridged by a ligand through two different atoms, each donating a pair of electrons, the distances between the donor sites could have an influence on the distances between the metal atoms. This might be independent of the attractive or repulsive forces between the metal centres. An example of such a control is obvious when one compares the series of complexes illustrated in figure 1 . In all cases the N-C-N bridged metal centres (Cotton et al 1988) are further apart than the N-N-N bridged clusters (Corbett et al 1975). This distance between the ligating atoms, which is the geometric distance between the coordinating atoms $\left(r_{g}\right)$ could be taken as a parameter for judging the extent to which different ligands influence the metal-metal distance. However, consider a hypothetical ligand where the two electron donor sites, $\mathrm{L}$ and $\mathrm{L}^{\prime}$, are separated by a distance $r_{g}$, the electron pair available for donation to the metal on $\mathrm{L}$ could be directed away from the other atom $\mathrm{L}^{\prime}$ as shown in 


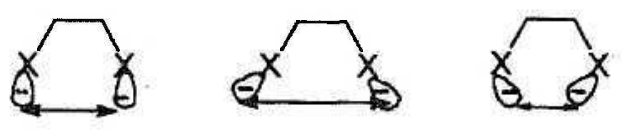

Figure 2. Variation of $r_{e}$ and $\mathrm{r}_{g}$.

figure 2 (centre). In this situation the M-M distance dictated by the ligand could be much larger than $r_{g}$. Alternatively the electron pair could be directed in the direction of $\mathrm{L}^{\prime}$ (figure 2, right). The latter situation would force the metal atoms to come close to one another. In either of these situations the geometric distance between the ligating atoms is not indicative of the metal-metal distance dictated by the, ligand. One reaches a wrong conclusion about M-M interactions from the value of $r_{g}$. This was first pointed out by Hoffman and coworkers (Merz and Hoffman 1988).

Of greater significance are the angles subtended by the non-bonded pair of electrons on the ligating atoms. This allows one to define electronic bite angles which would help one to discern the extent to which the ligands control the M-M distances. The presence of M-M interactions, if any, would be apparent from the deviations from these ligand-determined bite angles. A reliable estimate of the bite angles can be obtained from semi-empirical calculations available in the MOPAC package (Abraham et al 1993). Using the MNDO/III program (Stewart 1990) the preferred direction of approach of a test electrophile $\left(\mathrm{H}^{+}\right)$towards the ligating atoms of the bridging ligand can be estimated. The advantage of using the proton as a test electrophile is that by doing so, one eliminates all the complications and bias that arise due to metal-metal interactions, So also, by optimizing the position of the proton, the preferred approach of the test electrophile could be obtained. One could, in principle, use the alkali metal ion, modelled by a positive charge "sparkle" in the MNDO program, as a test electrophile. However the geometrical parameters related to the sparkle cannot be optimised.

For a particular ligand, the bite requirements are obtained by carrying out the calculation with the ligand fixed in the geometry found in the crystal structure of the metal complex. Optimising the bond distance and angles of proton attached to the ligating atom reveals the directionality of the non-bonded electron pair. It is instructive to compare the bite angles for a typical hard donor $\mathrm{N}$ and a soft donor $\mathrm{S}$. The ideal bite angle at an $s p^{2} \mathrm{~N}$ using this procedure is calculated to be $121^{\circ}$, while that at $\mathrm{RS}^{-}$is much smaller, $102^{\circ}$. These values are consistent with the computed and experimental geometries of acid-base complexes involving $\mathrm{N}$ and $\mathrm{S}$ donor molecules (Smith et al 1982; Rajappa et al 1989). It is important to note the variation of the energy as a function of the bite angles. The energy loss on deviating from the predicted bite angle is much larger at $\mathrm{N}$. The flatness of the electrophilic surface near the sulphur atom is compatible with its softness (Pearson 1990). This flatness indicates that the electrophile may approach the donor sulphur atom at a wide range of angles. The $\mathrm{Cu}-\mathrm{S}-\mathrm{Cu}$ bridging angles involving the sulphide ligand for example, vary from about $70^{\circ}$ to about $135^{\circ}$ in various crystallographically characterised copper complexes. The donor orbitals of the polarizable sulphur atom can accommodate the approaching electrophile in a wide range of angles.

The ideal coordination angles computed for various ligands found in polynuclear copper complexes show that $\mathrm{Cu}(\mathrm{I})-\mathrm{Cu}(\mathrm{I})$ distances are determined by the bite angles of the ligands (Abraham 1994). Although these results are entirely consistent with the 
conclusions of other workers in this area (Cotton et al 1988; Lee and Trogler 1990), one needs to show that the procedure adoped is indeed capable of identifying cases where $\mathrm{M}-\mathrm{M}$ bonds are involved. Hence a study of gold complexes has been taken up. In view of the predicted flatness of the potential energy surface of ligating $S$ atoms, one would expect the sulphur coordinated gold complexes to show the greatest deviations if any from predicted bite angles.

\subsection{The $d^{10}$ gold (I) system}

An intriguing phenomenon in gold chemistry which has received attention in both theoretical and experimental studies is the propensity for gold(I) atoms (Pyykko et al 1994; Assmann et al 1995; Jones et al 1995) to cluster due to the weak bonding interactions between the closed shell metal ions. Numerous gold(I) complexes with metal-metal separations of $2.78 \mathrm{~A}$ to $3.25 \mathrm{~A}$ which are less than the van der Waal's radius for gold are known to exist (Khan et al 1988; Nakamoto et al 1993; Mingos et al 1995). Other studies on multinuclear gold complexes have also shown that these attractive gold(I)-gold(I) interactions persist even in solution (Narayanaswamy et al 1993). The strength of gold-gold interactions has been estimated to be around $5-15 \mathrm{kcal} / \mathrm{mol}$ (Assefa et al 1995).

Fackler and coworkers have synthesized a series of dinuclear bridged complexes and a tetranuclear complex all of them bridged by sulphide ligands (figure 3). These complexes provide an excellent framework for the study of weak metal-metal interactions which are said to be brought about by relativistic contraction of the orbitals on Au. Compound 3.1 $\left[\mathrm{Au}_{2}\left(\mu\right.\right.$-S $\left(\mathrm{CH}_{2}\right)_{3} \mathrm{~S}(\mu$-dppm) $](\mathrm{dppm}=$ to(diphenylphosphinomethane $\left.)\right)$ has a close goldgold distance of $3.128 \mathrm{~A}$. While nearly linear $\mathrm{S}-\mathrm{Au} \sim \mathrm{P}$ angles are observed, the slight deviation $\left(6-10^{\circ}\right)$ from linearity is probably due to the twist of the propylene chain which is needed to maintain gold-gold contacts. This compound is also found to be luminescent under UV radiation. Fackler and others conclude that the presence of attractive M-M interactions is indicated by comparison of the S-S bite distance (4.122 A) which is considerably longer than the corresponding metal-metal distance $(3 \cdot 128 \AA)$ in the complex. Similarly, the metal-metal distance for complex 3.2, $\left[\mathrm{Au}_{2}\left(\mu-\mathrm{S}_{2} \mathrm{C}_{2}(\mathrm{CN})_{2}\right)\left(\mathrm{PPh}_{3}\right)_{2}\right]$ $(3 \cdot 116 \mathrm{~A})$ is significantly shorter than the corresponding $\mathrm{S}-\mathrm{S}$ distance (3.490 A). So also, the S-S distance (3.399 A) in complex (3.3) $\left[\mathrm{Au}_{2}\left(\mu-\mathrm{S}_{2} \mathrm{C}_{6} \mathrm{H}_{4}\right)\left(\mathrm{PPh}_{3}\right)_{2}\right]$ is much larger than
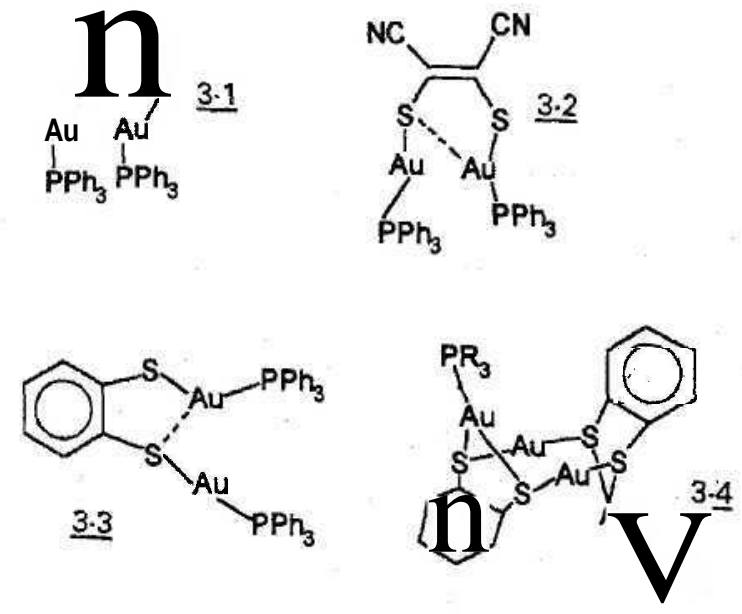

Figure 3. Thiolate bridged gold(I) complexes. 
the gold-gold separation of 3.149 A. These distances are shown in table 1. At first sight, the data would seem to imply the presence of bonding interactions between the metal centres. However, as detailed earlier, concluding that $\mathrm{Au}-\mathrm{Au}$ interactions are responsible for the shorter metal-metal distances rather than the S-S distances, one could be making a dangerous over-simplification. The geometric bite does not take into account the directionality of the donor orbitals. On the other hand, the true bite requirements of the ligand would be better represented by the electronic bite angles of the ligand.

Again the test electrophile, the proton, was employed to determine the preferred direction of approach of metals of the coordinating atoms of the ligands in the gold complexes. The ideal coordination angles computed for the ligand and for those found in the complex are listed in table 1.A striking difference in the results obtained from the calculations performed on the gold(I) system as compared to those carried out on the copper(I) system is evident from the observed deviations. It may be recalled that in the copper(I) system, the preferred geometry of the protons obtained by MNDO calculations was almost the same as that in which the metals were present. In the case of the gold(I) system, the calculated ideal bite angles of the ligand were in the range of the angles present in the crystal geometry of the complex. However, the ideal dihedral angles calculated by the MNDO method were considerably different from the value observed for the metal in the complex (deviations up to $95^{\circ}$ are observed). It is not the bite angle requirements of the ligand that dictate the position of the metals in these complexes! This deviation from the ideal geometry can be explained by the presence of attractive interactions between the gold(I) centres.

Table 1. Reduced overlap populations for gold dimers

\begin{tabular}{|c|c|c|c|c|}
\hline \multirow[b]{2}{*}{ Complex } & \multicolumn{2}{|c|}{ Inter-atomic distances } & \multicolumn{2}{|c|}{$\begin{array}{l}\text { Reduced overlap } \\
\text { populations }\end{array}$} \\
\hline & S-S & $\mathrm{Au}-\mathrm{Au}$ & Core & Complex \\
\hline $3 \cdot 1$ & $4 \cdot 122$ & $3-128$ & 0.027 & 0.036 \\
\hline $3 \cdot 2$ & $3 \cdot 490$ & $3 \cdot 116$ & 0.028 & 0.015 \\
\hline $3 \cdot 3$ & 3.399 & $3-149$ & 0.025 & 0.010 \\
\hline $3 \cdot 4$ & 3.399 & 3.099 & 0.029 & 0.008 \\
\hline
\end{tabular}

Table 2. Observed and calculated ligand bite angles.

\begin{tabular}{lcrrrr}
\hline & \multicolumn{2}{c}{ Crystal geometry } & & \multicolumn{2}{c}{ MNDO optimised geometry } \\
\cline { 2 - 3 } \cline { 5 - 6 } Complex & Au-S-C & Au-S-C-C & & H-S-C & H-S-C-C \\
\hline $3 \cdot 1$ & $107 \cdot 3$ & $100 \cdot 9$ & & $98 \cdot 9$ & $167 \cdot 4$ \\
$3 \cdot 2$ & $104 \cdot 3$ & $130 \cdot 0$ & & $99 \cdot 5$ & $170 \cdot 5$ \\
& $106 \cdot 4$ & $6 \cdot 5$ & & $101 \cdot 8$ & $101 \cdot 3$ \\
$3 \cdot 3$ & $103 \cdot 9$ & $71 \cdot 0$ & & $99 \cdot 5$ & $140 \cdot 9$ \\
& $107 \cdot 9$ & $-2 \cdot 4$ & & 101.9 & $-22 \cdot 8$ \\
$3 \cdot 4$ & $99-7$ & $-85 \cdot 3$ & & $99-0$ & $-100 \cdot 7$ \\
& $106 \cdot 8$ & $6 \cdot 1$ & & $96 \cdot 6$ & $66 \cdot 6$ \\
& $105 \cdot 3$ & $54 \cdot 4$ & $98-4$ & $54 \cdot 4$ \\
\hline
\end{tabular}


EHT calculations were also performed on this system and the reduced overlap populations (ROP) of the core and complex are listed in table 2 . Though the values are not large, they do indeed reveal that there are metal-metal interactions. A significant feature is that, in the first case, the ROP values actually increase $(\approx 0.01)$ upon the introduction of the ligand, unlike the other three complexes where there is a decrease $(\approx 0.01-0.02)$ in the ROP values. In the first case, it is possible that this is a case where the ligand has induced metal-metal interaction. The ligand helps in increasing the bonding interactions between the metal centres through 3-centre-2-electron bonding. The ROP values of this complex are significantly higher than the other three complexes even though the metal-metal distances are comparable, which means that there are probably two effects, metal-metal relativistic interactions as well as ligand mediated metal-metal interactions. These two effects act in a concerted fashion to bring about the observed short(I)-Au(I) distances. The potential of the procedure in predicting the presence of metal-metal interactions in $d^{10}$ systems with short metal-metal distances is well illustrated by these studies on gold dithiolate complexes.

\subsection{Ligand induced metal-metal interactions}

The analysis is slightly more complicated in the case of ligands which bridge two metal centres through a single atom. It has been shown for example that a measure of the preferred angle between the donor lone pairs on sulphur could be obtained by placing two protons with various HSH angles about the ligand. Full optimization at the MNDO level of the parameters related to the protons gave an angle of $96^{\circ}$ which may be considered to be the ideal M-S-M angle in the absence of additional electronic effects. Examination of the M-S-M bridges characterised to date reveal a rather complex situation. Both acute and obtuse bridges have been observed. In the case of two nearly identical clusters, one had an acute angle and short metal metal distances (Abraham et al 1993) and the other had angles close to $90^{\circ}$ and longer $\mathrm{Cu}-\mathrm{Cu}$ distances (Narasimhamurthy et al 1989). However in the tetrahedral clusters (Abraham et al 1993), it was shown that there was an additional complicating feature. The topology of the $\mathrm{Cu}_{4}^{+}$unit spanned by four 3-atom ligand bridges dictated the presence of acute $\mathrm{Cu}-\mathrm{S}-\mathrm{Cu}$ angles.

To determine the effect of the M-X-M angle on metal-metal interactions, EHT calculations were performed on a single model system with various $\mathrm{X} \sim$ ligands bridging a $\mathrm{Cu}_{2}^{2+}$ unit. For a given fixed a $\mathrm{Cu}-\mathrm{Cu}$ distance of $2.8 \mathrm{~A}$, the system was found to be destabilized on the basis of sum of one-electron energies as the $\mathrm{Cu}-\mathrm{X}-\mathrm{Cu}$ angle was decreased from acute to obtuse angles. This is primarily due to the loss in $\mathrm{Cu}-\mathrm{X}$ bonding. Interestingly, the $\mathrm{Cu}-\mathrm{Cu} \mathrm{ROP}$ values are higher at more acute angles as given in table 3. For example, for $\mathrm{X} \sim=\mathrm{RS}^{-}$, the metal-metal ROP is as large as 0.06 at an angle of $65^{\circ}$. However, the value becomes negative, taking a value of -0.01 at $8^{\circ}$, indicating antibonding interactions. Another interesting variation is the extent of antibonding in these complexes which increases with increased $\pi$ donation by the ligand. Thus reduced overlap populations between the two copper centres are greater when they are bridged by $\mathrm{OH}^{-}$than when $\mathrm{O}^{2} \sim$ is present as a bridge. A comparison of $\mathrm{O}^{2-}$ and $\mathrm{S}^{2-}$ suggests that bridging atoms which are larger decrease the M-M interactions more effectively. Furthermore, pure $a$ donors such as $\mathrm{H} \sim$ are extremely efficient in increasing the reduced overlap population between the metal centres. The hydride bridge presents a special case as there is no $\pi$ type of orbital on the bridge and 
Table 3. Reduced overlap populations $\left(\times 10^{3}\right)$ computed from EHT calculations

\begin{tabular}{|c|c|c|c|c|c|c|c|c|c|c|}
\hline \multirow{3}{*}{ Bridge angle } & \multicolumn{8}{|c|}{ System studied } & & \\
\hline & \multicolumn{2}{|c|}{$\mathrm{Cu}-\mathrm{Cl}-\mathrm{Cu}$} & \multicolumn{2}{|c|}{$\mathrm{Cu}-\mathrm{OH}-\mathrm{Cu}$} & \multicolumn{2}{|c|}{$\mathrm{Cu}-\mathrm{O}-\mathrm{Cu}$} & \multicolumn{2}{|c|}{$\mathrm{Cu}-\mathrm{S}-\mathrm{Cu}$} & \multicolumn{2}{|c|}{$\mathrm{Cu}-\mathrm{H}-\mathrm{Cu}$} \\
\hline & $\mathrm{Cu}-\mathrm{Cu}$ & $\mathrm{Cu}-\mathrm{Cl}$ & $\mathrm{Cu}-\mathrm{Cu}$ & $\mathrm{Cu}-\mathrm{OH}$ & $\mathrm{Cu}-\mathrm{Cu}$ & $\mathrm{Cu}-\mathrm{O}$ & $\mathrm{Cu}-\mathrm{Cu}$ & $\mathrm{Cu}-\mathrm{S}$ & $\mathrm{Cu}-\mathrm{Cu}$ & $\mathrm{Cu}-\mathrm{H}$ \\
\hline $82 \cdot 3$ & 7 & 437 & 31 & 183 & 25 & 170 & 7 & 598 & 74 & 188 \\
\hline $80 \cdot 6$ & 11 & 411 & 32 & 165 & 27 & 153 & 10 & 572 & 73 & 177 \\
\hline 78.9 & 14 & 386 & 33 & 148 & 29 & 138 & 13 & 545 & 72 & 166 \\
\hline $77 \cdot 3$ & 17 & 360 & 34 & 133 & 31 & 123 & 16 & 519 & 71 & 155 \\
\hline $75 \cdot 8$ & 21 & 336 & 35 & 118 & 32 & 109 & 20 & 493 & 70 & 145 \\
\hline $74 \cdot 2$ & 24 & 311 & 35 & 104 & 33 & 97 & 23 & 467 & 68 & 134 \\
\hline
\end{tabular}


reduced overlap populations between two $\mathrm{Cu}-\mathrm{Cu}$ centres are large even with obtuse angles. Due to the smaller $\mathrm{Cu}-\mathrm{H}$ distances, the induced $\mathrm{Cu}-\mathrm{Cu}$ bonding is more effective at short $\mathrm{Cu}-\mathrm{H}$ distances and obtuse $\mathrm{Cu}-\mathrm{H}-\mathrm{Cu}$ angles. This indeed to be expected from the molecular orbital description of the bonding (vide infra). Thus, there is a direct connection between the acute bridging angles and the short metal-metal distances in $d^{10}$ clusters.

The above results are entirely consistent with previous studies (Cui and Kertesz 1990; Alemany and Alvarez 1992; Subramanian and Hoffmann 1992) and can be interpreted in terms of the nature of $\mathrm{Cu}-\mathrm{X}-\mathrm{Cu}$ bonding. In analogy to the bonding patterns in boranes, two extreme descriptions of closed and open C-centre bonding models have been proposed. If the angle at the bridging ligand is acute, a closed 3-centre 2-electron bond is indicated (figure 4). In this arrangement, the metal-metal interaction is attractive. On the other hand, an open 3-centre bond has been invoked for bridges with wider $\mathrm{Cu}-\mathrm{X}-\mathrm{Cu}$ angles. The interaction involves a $p$ type lone pair on $\mathrm{X}$ and an antisymmetric combination of metal orbitals. As the overlap becomes more effective, the interaction between the metal atoms becomes correspondingly antibonding. Ligands such as a hydride can only have closed 3-centre 2-electron bonding and hence will result in short $\mathrm{Cu}-\mathrm{Cu}$ distances. This has indeed been experimentally observed (Ho and Bau 1983, 1984). Increasing the effectiveness of $\pi$ donation would increase the antibonding interactions between the copper atoms and reduce the ROPs. Thus in most cases both the closed and open bonding interactions are generally possible resulting in the reduced $\mathrm{Cu}-\mathrm{Cu}$ ROPs with inclusion of ligands.

The importance of ligand induced metal-metal interactions in determining metalmetal separations would be best exposed in systems where ligands are involved in 3-centre 2-electron or orbital-rich bridges. A rather ubiquitous trinuclear fragment $\mathrm{M}_{3}(\mathrm{dppm})_{3}$ qualifies for this study. Figure 5 gives some of the complexes where $\mathrm{M}_{3}$ (dppm) $)_{3}$ clusters are capped by various bridges. The variation of metal-metal distances with various caps shows how the bridging ligand clearly influences the metal-metal distances. In order to probe if the reduced M-M distances are due to attractive M-M interactions, an EHT study was taken up in the case of the $\mathrm{Cu}_{3}(\mathrm{dppm})_{3}$ clusters. Some of these clusters are doubly capped (figure 6) and crystallographic results are available for several of them. These complexes synthesized earlier (Diez et al 1993) have a basic framework of an isosceles triangle of copper(I) atoms with a dppm ligand bridging each edge to form a roughly planar $\mathrm{Cu}_{3} \mathrm{P}_{6}$ core. These triangulo copper(I) complexes are either mono or bicapped ligands. The bridging acetvlide ligand for example, coordinates to the three coppers in an asymmetric $\mu_{3} \eta^{1}$ fashion. The monocapped species adopts a bent orientation which notably reduces the formal distance of the acetylene $\mathrm{C} \beta$ atom to the $\mathrm{Cu}_{3}^{\text {s+ }}$ plane. The distance between the coordinating atoms and the coppers are significantly different in each case. The most
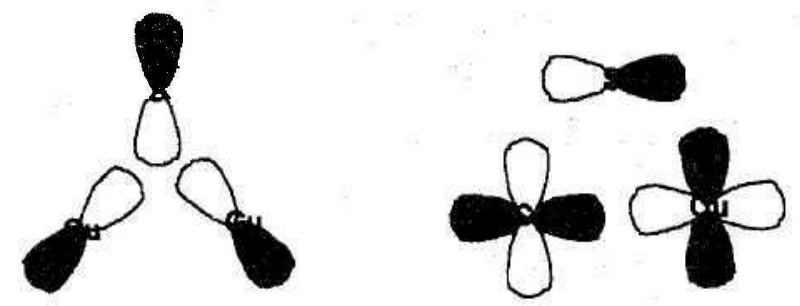

Figure 4. Three-centre bonding in metal complexes. 


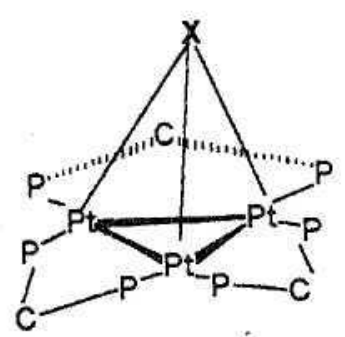

$X=\operatorname{Re}(\mathrm{CO})_{3}, \operatorname{ReO}{ }_{3}, \operatorname{Re}(\mathrm{CO})_{3} \mathrm{O}_{3}, \operatorname{ReO} 6$, etc

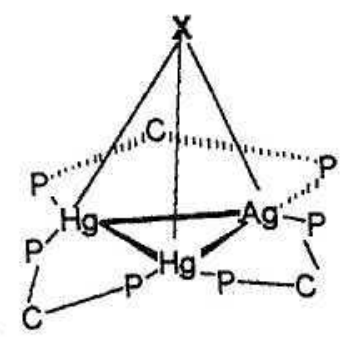

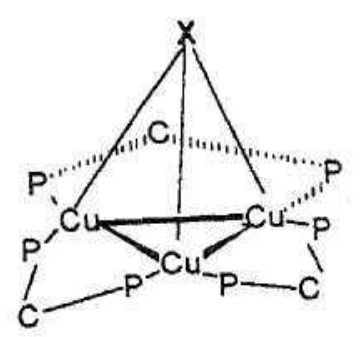

$\mathrm{X}^{*} \mathrm{C}=\mathrm{CPh}, \mathrm{OH}, \mathrm{Cl}$

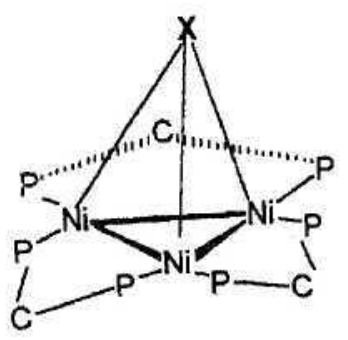

Figure 5. Triangular clusters bridged by dppm.

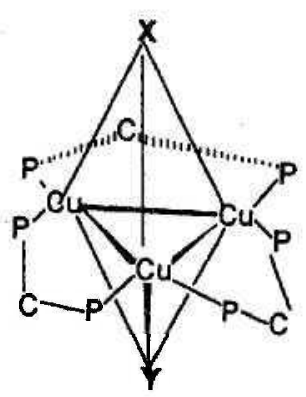

Figure 6. Bicapped tricopper clusters.

striking feature is that the monocapped alkynyl complex shows among the three complexes the larger $\mathrm{Cu}-\mathrm{Cu}$ distances but the shortest $\mathrm{Cu}-\mathrm{C}$ distance. In contrast the introduction of one additional chloride or acetylide ligand to form a bicapped system leads to the shortening of the copper-copper distance while the copper-carbon distances are increased. The $\mathrm{Cu}-\mathrm{Cu}$ distances in the bicapped complexes, with two $\mathrm{Cl} \sim$ ligands, and in the one with $\mathrm{OH} \sim$ are the longest. It was precisely this observation that led to the suspicion that this was indeed a case of ligand mediated metal-metal interaction. The bonding in this sytem has been described as a 4c-2e bridge in the case of the monocapped species or a $5 \mathrm{c}-4 \mathrm{e}$ bridge in the case of the bicapped species. In either case, one might expect the outcome of having an orbital-rich situation to be similar to the $\mathrm{Cu}_{2} \mathrm{X}$ system. 
Table 4. Reduced overlap populations $\left(\times 10^{3}\right)$ computed from EHT calculations for triangular copper clusters.

\begin{tabular}{lcrcll}
\hline Complex & & \multicolumn{2}{c}{ Reduced overlap populations } & \\
\cline { 1 - 1 } & $\mathrm{Y}$ & & $\mathrm{Cu}-\mathrm{Cu}$ & $\mathrm{Cu}-\mathrm{X}$ or $\mathrm{Cu}-\mathrm{Y}$ & \multicolumn{1}{c}{ Comments } \\
\hline & & 0.062 & & ROP of the core \\
$\mathrm{C}=\mathrm{C}-\mathrm{H}$ & & 0.071 & 0.261 & Monocapped core \\
$\mathrm{C}=\mathrm{C}-\mathrm{H}$ & & 0.069 & 0.270 & Tilted monocapped \\
$\mathrm{C} \equiv \mathrm{C}-\mathrm{H}$ & $\mathrm{C}=\mathrm{C}-\mathrm{H}$ & 0.036 & 0.240 & Dicapped core \\
$\mathrm{C} \equiv \mathrm{C}-\mathrm{H}$ & $\mathrm{C}=\mathrm{C}-\mathrm{H}$ & 0.071 & 0.170 & Dicapped core \\
$\mathrm{CO}$ & & 0.071 & 0.250 & Monocapped $\pi$ acceptor \\
$\mathrm{Cl}$ & & 0.052 & $0-130$ & Monocapped $n$ donor \\
$\mathrm{Cl}$ & $\mathrm{Cl}$ & -0.021 & 0.327 & Dicapped core \\
\hline
\end{tabular}

The results of the EHT calculations are given in table 4. The effect of capping ligands on the bonding interactions in the cluster is probed using a method of analysis similar to the one used for the study on the tetrameric and hexameric copper(I) complexes. In order to have a highly symmetrical system which would make the interpretation of the results less involved, an equilateral triangle of copper atoms was employed in the study. The bridging ligand(s) were placed perpendicular to the plane containing the metal atoms and were bonded to the metal atoms in a symmetrical $\mu_{3} \eta^{1}$ fashion. The bridging dppm ligands were not included to help assess the role of only the mono- and bicapped ligands in bringing about metal-metal interactions. All the complexes were modelled using the program Insight $\mathrm{II}^{1}$. The interactions between the metal centres placed at a distance of $2.60 \mathrm{~A}$ in the triangulo $\mathrm{Cu}_{3}^{3+}$ core were first computed. One acetylide ligand was then introduced to cap the tricopper plane at a distance of $2.12 \mathrm{~A}$ from it and the Reduced Overlap Populations (ROPs) were then determined. An increase in the ROP (ca. 0.01) reveals that the introduction of the ligand enhances the interaction between the metal centres and is greater than the interactions in the naked $\mathrm{Cu}_{3}^{3+}$ core. When this acetylide ligand was tilted by $10^{\circ}$ to the tricopper plane, the metal-ligand interactions increased at the expense of the metal-metal interactions as seen by the decrease in the ROP between the metal centres and an increase in the M-L ROPs. Next, the second ligand was introduced to cap the tricopper plane from below, again at the same distance. Contrary to the expectation based on experimental observation where the copper-copper distances decreased, the introduction of the second ligand actually lowered the ROPs by a factor of 0.02 . However, a closer examination of the $\mathrm{Cu}-\mathrm{C}$ distances in the bicapped cluster shows that the $\mathrm{Cu}-\mathrm{C}$ distances increased to $2.32 \mathrm{~A}$ making the bridges more acute. When the calculations were repeated at this $\mathrm{Cu}-\mathrm{C}$ distance of $2.32 \mathrm{~A}$, the ROPs increased significantly.

Next, the role of the strong $n$ donor ligands in influencing the metal-metal interactions were investigated. When two chlorides were introduced to form the bicapped species, the reduced overlap populations between the metal centres actually became negative, indicating antibonding interactions between the metal centres, that showed bonding interactions for the bicapped acetylide complex at the same metal-metal distances. Similarly the ${ }^{1}$ Modelling results obtained using the software program "Insight II" from Biosym Technologies
of San Diego, CA. 
$\mathrm{OH}^{-}$ligand also reduced the metal-metal attractive interactions. Both the $\mathrm{OH}^{-}$and the $\mathrm{Cl}^{-}$ligands have $\pi$-donor and $\sigma$-donor capabilities and they do not help in enhancing metal-metal interactions. If this were to be true, a carbonyl ligand or a hydride which has predominantly sigma bonding properties and $\pi$ acid properties will promote metal-metal attractive interactions as did the acetylide ligand. This was found to be true with the reduced overlap populations being as high as in the acetylide case. Thus depending upon the $\pi$-acceptor and $\sigma$-donating capabilities of the ligands, the metal-metal interactions can either be enhanced to have bonding interactions between metal centres or efficiently destroyed to have only antibonding interactions. These results clearly demonstrate how the ligand mediates in bringing about positive interactions between the metal centes.

Synthesis of a complex with a specific capping ligand, however, is not always easy. In fact some of the clusters studied theoretically such as the hydride capped $\mathrm{Cu}_{3}$ cluster may not be formed for the simple reason that there are not enough electrons for skeletal bonding if one assumes it is a 16-valence electron complex. Skeletal bonding in the case of metals which form 16-valence electron complexes has been worked out (Mingos 1984). The copper cluster requires that there be 48 valence electrons when it is capped on both sides and 46 valence electrons when it is capped on one side. A six-electron donor such as the $\mathrm{OH}^{-}$leads to an isosceles triangle of copper atoms when it forms a monocapped structure since the electron count indicates a nido structure. Attempts to prepare the carbon monoxide capped trimer have not been successful to date (Bera et al unpublished work). In retrospect, this is not surprising since $\mathrm{CO}$ is a very poor $n$ donor. Preliminary results from an X-ray crystallographic study suggest that the $\mathrm{Cu}-\mathrm{Cu}$ distances in the $\mathrm{Cu}_{3}(\mathrm{dppm})_{3}$ core bridged by two aryloxide ligands are in the range predicted by the above analysis (Wycliff et al, unpublished results). Further, a planar $\mathrm{Cu}_{4}$ cluster, bridged by hydrides, appears to have short $\mathrm{Cu}-\mathrm{Cu}$ distances (Sekhar et al unpublished results). Tuning metal-metal distances with ligands indeed appears to be a feasible goal.

\section{Acknowledgements}

We wish to thank the Council of Scientific and Industrial Research, New Delhi for generous financial assistance, Prof J Chandrasekhar for stimulating discussions and Profs. $\mathrm{J}$ Fackler and R Hoffman for preprints of their papers.

\section{References}

Abraham S P 1994 Synthesis, structure, reactivity and bonding aspects of oligomeric copper(I) complexes, $\mathrm{PhD}$ thesis, Indian Institute of Science, Bangalore

Abraham S P, Narsimhamurthy N, Netaji M, Samuelson A G 1993a Inorg. Chem. 321739

Abraman S P, Samuelson A G and Chandrasekhar J 1993b Inorg. Chem. 326107

Alemany P and Alvarez S 1992 Inorg. Chem. 314266

Assefa Z, McBurnett B G, Staples R J and Fackler Jr J P 1995 Inorg. Chem. 3475

Assmann B, Angermaier K and Schmidbaur H 1995 Inorg. Chem. 3475

Corbett M, Hoskins B F, McLeod N J and Day B P O 1975 Aust. J. Chem. 282377

Cotton F A and Wilkinson G 1988 Inorganic chemistry 5th edn (New York: John Wiley and Sons)

Cotton F A, Feng X, Matusz M and Poli R 1988 J. Am. Chem. Soc. 110 (a) 1144,(b) 7077

Cui C X and Kertesz M 1990 Inorg. Chem. 292568

Diez J, Gamasa M P, Gimeno J, Elena L, Aguirre A and Granada S G 1993 Organometallics. 122213

Ho D N and Bau R 1983 Inorg. Chem 224079

Ho D M and Bau R 1984 Inorg. Chim. Acta 84213

Hoffmann R 1963 Chem. Phys. 391397 
Jones W B, Yuan J, Narayanaswamy R, Young M A, Elder R C, Bruce A E and Bruce R M 1995 Inorg. Chem. 341996

Khan N I Md, Wang S, Heinrich D D and Fackler J P 1988 Acta Crystallogr. C44 822

Lee S W and Trogler W C 1990 Inorg. Chem. 291659

Merz K M and Hoffmann R 1988 Inorg. Chem, 272120

Mingos D M P 1984 Acc. Chem. Res. 17311

Mingos D M P, Yau J, Menzer S and Williams D J 1995 J. Chem. Soc. Dalton Trans 319

Nakamoto M, Hiller W and SchmidbaurH 1993 Chem. Ber. 126605

Narasimhamurthy N, Samuelson A G and Manohar H 1989 J. Chem. Soc., Chem. Commun. 231803

Narayanaswamy R, Young M A, Parkhurst E, Ouellette M, Kerr M E, Ho D M and Elder R C 1993 Inorg. Chem. 322506

Park A E Y and Kanatzidis M G 1990 Angew. Chem., Int. Ed. Engl. 29914

Pearson R G 1990 Coord. Chem. Rev. 100403

Pyykko P, Li J and Runeberg N 1994 Chem. Phys. Lett. 218133

Rajappa S, Bhawal B M, Rakeeb A, Deshmukh A S, Manjunatha S G and Chandrasekhar J $1989 \mathrm{~J}$. Chem. Soc., Chem Comnun. 221729

Smith F S, Chandrasekhar J and Jorgensen W L 1982 J. Phys. Chem. 863308

Stewart J P P 1990 J. Computer Aided Mol. Design 41

Subramanian L and Hoffmann R 1992 Inorg. Chem. 311021 